\title{
Calcium intake in health maintenance - a systematic review
}

\author{
Kirsti Uusi-Rasil*, Merja U. M. Kärkkäinen ${ }^{2}$ and \\ Christel J. E. Lamberg-Allardt ${ }^{3 *}$ \\ 'UKK Institute for Health Promotion Research, Tampere, Finland; ${ }^{2}$ Academy of Finland, Helsinki, Finland; \\ ${ }^{3}$ Department of Food and Environmental Sciences, University of Helsinki, Helsinki, Finland
}

\section{Abstract}

Background: Calcium $(\mathrm{Ca})$ is an essential nutrient for the human body. Despite lively research, there is uncertainty about $\mathrm{Ca}$ requirements in terms of desirable health outcomes including an upper intake level above which the potential for harm increases.

Objectives: The aim was to conduct a review to update requirements and desirable or harmful health effects of $\mathrm{Ca}$ on the current scientific evidence.

Methods: We searched Medline and Swemed from January 2000 to December 2011 and included all systematic reviews that reported $\mathrm{Ca}$ supplementation or usual $\mathrm{Ca}$ intake on health outcomes. Meta-analyses, randomized clinical trials and cohort studies were included in the second search between May 2009 and March 2011 and an additional search covering studies till the end of 2011. This review concentrated on studies reporting independent effects of $\mathrm{Ca}$, although a few recent trials report sole effects of $\mathrm{Ca}$ on health outcomes, most trials use $\mathrm{Ca}$ in combination with vitamin $\mathrm{D}$ vs. placebo.

Results: In total, we reviewed 38 studies addressing the effects of $\mathrm{Ca}$ on bone, pregnancy-related outcomes, cancers, cardiovascular outcomes, obesity, and mortality. There was a lot of heterogeneity in the study protocols, which made it difficult to draw any strong conclusions. According to the literature, high $\mathrm{Ca}$ intake seems to have a small positive effect on bone mineral content (BMC) or bone mineral density (BMD) in children and postmenopausal women. We did not find any consistent evidence on the effects of $\mathrm{Ca}$ on bone health in premenopausal women or men. Also, the evidence that $\mathrm{Ca}$ supplementation reduces fracture incidence is scarce and inconsistent. Maternal diet may influence the peak bone mass of offspring but more studies are required. There was no overall effect of $\mathrm{Ca}$ intake on cancers. Ca was associated with a decreased risk of breast cancer and a slightly increased risk of prostate cancer in two of the three studies. No associations were found with other cancers. We found no consistent association between cardiovascular outcomes and $\mathrm{Ca}$ intake except for blood pressure. A small decrease of $2-4 \mathrm{mmHg}$ in systolic blood pressure was found in pregnant and in hypertensive subjects with $\mathrm{Ca}$ supplementation. Reviewed studies did not show consistent evidence relating $\mathrm{Ca}$ intake to either mortality or obesity.

Conclusion: Based on this evidence, there is no need to change the Nordic recommendations for Ca intake. However, due to heterogeneity in the studies it is difficult to interpret the results and provide single summary statement.

Keywords: Calcium intake; calcium requirements; disease prevention; osteoporosis; bone mineral density; health maintenance; health outcomes

To access the appendices to this article please see Supplementary files under Article Tools online

Received: 4 February 2013; Revised: 21 March 2013; Accepted: 10 April 2013; Published: 16 May 2013

$\mathrm{T}$ his systematic literature review (SR) is a part of the NNR5 project with the aim of reviewing and updating the scientific basis of the 4th edition of the Nordic Nutrition Recommendations (NNR) issued in 2004 (Nord 2004:13) (1). The NNR5 project is mainly focused on a revision of those areas in which new scientific knowledge has emerged since the 4th edition with special relevance for the Nordic setting. A number of SRs will form the basis for establishment of dietary reference values in the 5 th edition of NNR. 


\section{Aims}

The overall aim was to review the recent scientific data on requirements and health effects of calcium $(\mathrm{Ca})$ to update the current dietary reference values valid in Nordic countries.

The specific objectives of the review on health effects on $\mathrm{Ca}$ in human nutrition are as follows:

(1) Review the scientific evidence to determine, based on a set of agreed criteria, dietary reference values for $\mathrm{Ca}$ for different life stages (infants, children, adolescents, adults, elderly, and during pregnancy and lactation);

(2) Assess the requirement of $\mathrm{Ca}$ for adequate growth, development, and maintenance of health; and

(3) Assess the health effects of different intakes/ exposures of $\mathrm{Ca}$.

\section{Scientific background}

At full-term birth, the human infant accrues about 26-30 $\mathrm{g}$ of $\mathrm{Ca}$, most of which is present in the skeleton as calcium hydroxyapatite $\left(\mathrm{Ca}_{10}\left[\mathrm{PO}_{4}\right]_{6}[\mathrm{OH}]_{2}\right)$, which provides the rigidity necessary for the skeleton to function mechanically. When the Ca transfer from the placenta ceases at birth, the newborn infant is dependent on dietary $\mathrm{Ca}$. $\mathrm{Ca}$ is an important regulator of several body functions, such as muscle contraction, function of the nervous system, and blood clotting. Due to its vital importance, $\mathrm{Ca}$ concentration in intracellular and extracellular fluid is tightly regulated. Bone tissue serves as a reservoir and as a source of $\mathrm{Ca}$ for these critical metabolic needs through the process of bone remodelling.

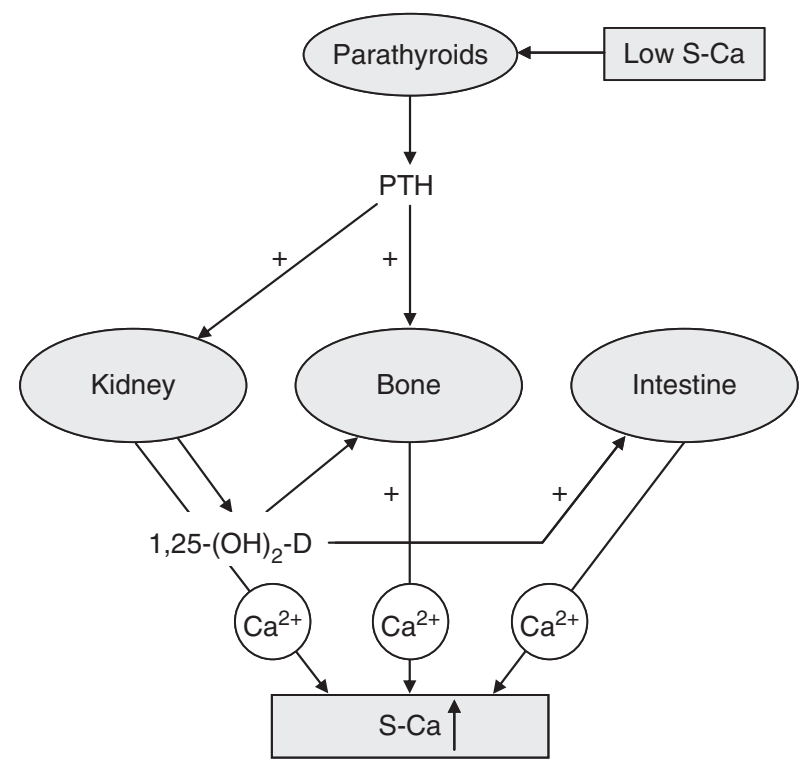

Fig. 1. Endocrine feedback system that maintains serum calcium concentrations: involvement of $1,25(\mathrm{OH})_{2} \mathrm{D}$ and parathyroid hormone (PTH).
The most important regulators of Ca metabolism (Fig. 1) in humans are parathyroid hormone $(\mathrm{PTH})$ and 1,25dihydroxyvitamin $\mathrm{D}\left(1,25-(\mathrm{OH})_{2} \mathrm{D}\right)$.

Bone is a dynamic and metabolically active tissue; it is constantly renewed at an average rate of $8-10 \%$ per year, and the body's need for Ca relative to skeletal growth and remodeling varies by life stage. The major physiological activities include bone accretion during skeletal growth and maintenance of bone mass after growth is completed. $\mathrm{Ca}$ balance studies have shown that $\mathrm{Ca}$ retention is significantly higher in adolescents than in adults with the same $\mathrm{Ca}$ intake. Later in adult life, net $\mathrm{Ca}$ is lost from the body when bone formation no longer balances with bone resorption. There are two different types of bone tissue, which are formed with the same cells and matrix elements, but they differ in their structure and function. The peripheral skeleton constitutes $80 \%$ of the skeletal mass, and is composed primarily of cortical bone. About $70 \%$ of the central skeleton is, in turn, trabecular bone. Trabecular bone, with its greater surface area, is metabolically more active and is thus more responsive to changes in mineral homeostasis, whereas the cortical bone fulfills mainly the mechanical and protective functions. In adults, bone modeling occurs less frequently than bone remodeling, particularly in trabecular bone. While the turnover rate of $2-3 \%$ per year in cortical bone is consistent with maintenance of mechanical properties, the turnover rate in trabecular bone is much higher.

Dietary calcium is classically associated with dairy products, and food supplies such as milk, yoghurt, and cheese are rich sources of $\mathrm{Ca}$, providing the majority of $\mathrm{Ca}$ in the general diet in the Scandinavian countries. In Finland (2) and Sweden (3), milk products provide more than $60 \%$ of the dietary calcium intake and in Norway (4) approximately $70 \%$. The mean intakes in adult women in these countries vary from 800 to 1,000 $\mathrm{mg} /$ day and in men from 1,000 to $1,200 \mathrm{mg} /$ day.

\section{Research/key questions for calcium}

(1) What is the relationship between $\mathrm{Ca}$ intake and different outcomes in different population and age groups?

(2) What is the relationship between $\mathrm{Ca}$ intake and well-established markers of different functional or clinical outcomes in different population and age groups?

(3) What is the effect of supplemental $\mathrm{Ca}$ on different outcomes in different population and age groups?

(4) What is the effect of Ca intake from different sources on $\mathrm{Ca}$ metabolism in different population and age groups?

(5) Which is the interaction of $\mathrm{Ca}$ intake from different sources with iron intake or iron status on health outcomes in different population and age groups? 
(6) Which is the UL (tolerable upper intake level) for $\mathrm{Ca}$ intake for different health outcomes in different population and age groups?

\section{Methods}

\section{Definitions}

This review focuses on publications reporting independent effects of $\mathrm{Ca}$, although a few recent trials report sole $\mathrm{Ca}$ effects on health outcomes, most trials use $\mathrm{Ca}$ in combination with vitamin D vs. placebo.

The indicators of exposure were dietary calcium, fortified foods, and supplementation exposure.

Publication types: Questions 1-4: SRs, Cochrane database systematic reviews, meta-analyses; Question 5: cohort studies (longitudinal or prospective studies), intervention studies; Question 6: for adverse effects: randomized controlled trial s(RCTs). Time frames for search: January 2000-April 2009; May 2009-June 2010; and July 2010-December 2011.

The following outcome measures were included:

- Pregnancy outcomes and growth

- Bone health

- All fractures

-Hip fractures

qVertebral fractures

- BMD/osteoporosis

- Bone mass

- Bone quality

- Muscle strength

- All cancers

- Breast cancer

- Colorectal cancer

- Prostate cancer

- Autoimmune diseases

- Diabetes type II

- Obesity/weight control

- Total mortality

- Cardiovascular disease clinical outcomes

The search terms are defined in Appendix A.

The following life stages were included: infants, children, adolescents, adults, elderly, and pregnancy and lactation.

The population groups in the search were primarily Caucasian.

\section{Search methods and terms}

Two expert reference librarians designed and conducted the electronic search strategy based on the research questions provided by the three investigators. The following electronic databases were searched: Medline and Swemed. The search was conducted using medical subject heading terms (MESH; see Appendix A). The search was done in two batches, the first covering January 2000-April 2009 and the second May 2009-June 2010 and July 2010February 2011. A complementary search was done at the end of January 2012 covering the period between the first searches until the end of December 2011. The search is documented in Appendix A. In the first search, the investigators focused only SRs and in the second SRs and randomized control trials, published after May 2009, except the study question 5 where all types of studies were included due to the less number of hits.

Furthermore, we used snowballing for SRs and RCTs, which was not in the original search.

\section{Selection of articles/studies, data collection, and analyses}

The investigators screened all abstracts individually from the searches, and later all the three investigators made a common decision on the full-text articles that had been required from the librarian. From the batches of full-text articles, we included those that met the criteria for SRs. In addition regarding study question 5, RCTs, intervention studies, and cohort studies were included. The fulltext articles were examined individually and the three investigators made a common decision on which articles should be included and which to be excluded. Eligible criteria for full-text articles were SR, matching the research questions and healthy population (not patients or medication). In the case of clinical studies and cohort studies, only studies from Europe, Australia, and North America were included. We recorded the reason for rejection of all full-text articles (Fig. 2).

Three authors first independently assessed trial quality and extracted data including adverse events.

\section{Quality assessment of studies}

The results of systematic reviews and meta-analyses were quality assessed and evaluated using the NNR5modified AMSTAR quality assessment tolls and incorporated in the evidence tables. Quality assessment of the RCTs and cohort studies was done according to the NNR guidelines.

\section{Participants}

We focused on populations in Europe and North America. However, if other populations were included in the SRs, we were usually not able to separate them.

\section{Exposure}

Dietary calcium or calcium supplements such as calcium carbonate, calcium citrate, calcium chloride, or calcium phosphates.

\section{Study quality}

There was a lot of heterogeneity in study subjects, methods, and protocols, making it difficult to interpret the results and provide single summary statement. The 


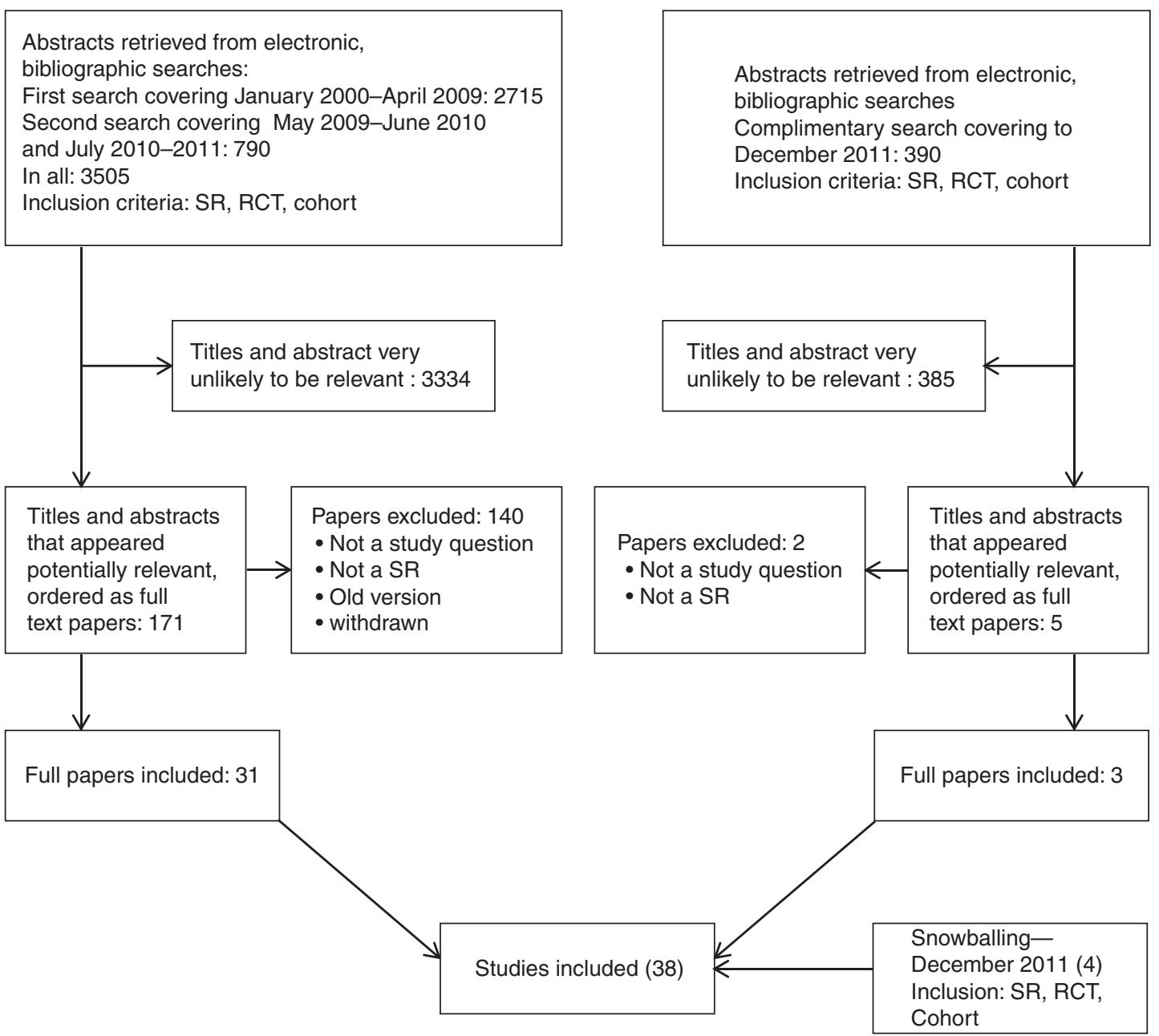

Fig. 2. Flow chart of the study selection.

sources and dose of Ca varied widely among the studies, as well as the methods used to assess the amount consumed. For many risk factors, the quality and strength or direction of association varies among studies. Study cohorts were mainly Caucasian participants.

\section{Publication bias}

Publication bias cannot be ruled out, since relevant studies were searched by the electronic databases, such as Medline and Swemed, unpublished or ongoing studies were not identified. The search was to the end of December 2011.

\section{Reporting and summarizing the evidence}

The evidence is summarized in the evidence tables, Appendix C, tables 1-6. The included and excluded studies are listed in Appendix B.

\section{Effects of $\mathrm{Ca}$ exposure on outcome measures}

\section{Health outcomes}

Characteristics of the included studies for each health outcome are shown in Evidence Tables 1-6.

\section{Bone health}

The results of bone health are shown in Evidence Table 1.

\section{Calcium accrual and bone health in childhood}

Calcium accrual. Since more than $99 \%$ of body $\mathrm{Ca}$ is present in the skeleton, an adequate $\mathrm{Ca}$ intake during the growth period may be critical in maximizing BMC. In their longitudinal study, Vatanparast et al. (5) reported the average accumulation of $\mathrm{Ca}$ (standard deviation, SD) in adolescent Caucasian boys and girls (9-18 years). Boys accrued 198.8 (74.5) g bone mass (BMC) per year, equivalent to 175.4 (65.7) $\mathrm{mg}$ calcium per day with the maximum accrual of $335.9 \mathrm{~g}$ from age 13 to 14 . Girls accrued 138.2 (64.2) g BMC per year, equalling 121.8 (56.6) $\mathrm{mg}$ calcium per day with the maximum annual BMC accrual of $226.0 \mathrm{~g}$ from age 12 to 13 .

Bone health. We found only one SR (graded A) and one meta-analysis (graded C) addressing bone health in children. We did not find any data reporting effects of Ca supplementation on bone fractures as an outcome in children. 
A systematic review of Winzenberg et al. (6) included RCTs of Ca supplementation either with Ca supplements or dietary $\mathrm{Ca}$ compared with a placebo, with a treatment period of at least 3 months. The participants were healthy children aged 3-18 years, and bone outcomes were measured after at least 6 months of follow-up. Nineteen RCTs $(N=2,859$ participants, out of them 1,367 were randomized to supplements, 1,426 to placebo) met inclusion criteria. $\mathrm{Ca}$ supplementation doses ranged from 300 to $1,200 \mathrm{mg} /$ day using calcium citrate, calcium carbonate, calcium phosphate, calcium lactate gluconate, calcium phosphate milk extract, or milk minerals as a source of $\mathrm{Ca}$. None of these studies used dairy foods as a supplement.

There was no statistically significant effect of $\mathrm{Ca}$ supplementation on BMD] $\left(\mathrm{mg} / \mathrm{cm}^{2}\right)$ at the femoral neck (10 studies) or lumbar spine (11 studies) standardized mean differences (SMD; 95\% CI) being 0.07 (from -0.05 to 0.19 ) and 0.08 (from -0.04 to 0.20 ), respectively. However, there was a small effect on total body BMC (g) ( 9 studies) SMD being $0.14(0.01-0.27)$, as well as on upper limb density (12 studies) $(0.14 ; 0.04-0.24)$. This effect is comparable to about $1.7 \%$ greater increase in supplemented groups. Only the effect in the upper limb persisted after supplementation ceased $(0.14 ; 0.01-0.28)$. In the subgroup analyses, treatment effects during supplementation were greater at all sites in females than males, though not statistically significantly. Baseline Ca intake, physical activity, pubertal stage, type of supplementation (milk extract or other), duration of supplementation, and exceeding the $\mathrm{Ca}$ threshold did not significantly modify the effect. They concluded that although there was a small effect of $\mathrm{Ca}$ supplementation in the upper limb, the increase in BMD is unlikely to result in a clinically significant decrease in fracture risk.

Huncharek et al. (7) did a meta-analysis evaluating the effects of calcium/dairy supplementation on bone health using BMC $(\mathrm{g})$ as the primary outcome. Initial pooling of 12 RCTs $(N=2,460)$ yielded a summary mean difference $(95 \% \mathrm{CI})$ in BMC between the Ca supplemented and placebo arms of $2.05 \mathrm{~g}$ (from -3.26 to $7.36 \mathrm{~g}$ ). Owing to the heterogeneity of the pooled data, the calculated summary mean difference in BMC is of dubious validity. When the papers with low baseline $\mathrm{Ca}$ intake were pooled (three studies), a summary mean difference was $49.9 \mathrm{~g}(24.0-76.6 \mathrm{~g})$ in total body BMC. Four RCTs contained data on lumbar spine BMC, but due to substantial differences across these reports, the authors could not further characterize the effect of $\mathrm{Ca}$ supplementation at the lumbar spine. They concluded that increased calcium/dairy intake significantly increases total body and lumbar spine BMC in children with low baseline intakes. However, it is improbable to demonstrate significant differences between groups when both groups are receiving physiologically adequate amounts of $\mathrm{Ca}$.
In conclusion, there was a small effect of $\mathrm{Ca}$ supplementation in the upper limb BMD and total body BMC. From a physiological point of view $\mathrm{Ca}$ is essential for the skeleton. Other factors, such as vitamin $\mathrm{D}$, may be crucial in the assessment of the role of $\mathrm{Ca}$ intake. Adequate vitamin $\mathrm{D}$ intake may be a crucial factor when assessing the role of $\mathrm{Ca}$ intake.

Bone health in pregnancy and fetal growth

We did not find any SR regarding $\mathrm{Ca}$ intake in pregnancy, but one RCT (graded C) and one longitudinal follow-up study (graded C).

In addition to genetic and lifestyle factors, adequate maternal nutrition during pregnancy may be an important contributor to fetal growth and bone health. In an RCT, healthy primiparous women ( $<20$-week gestation) with $\mathrm{Ca}$ intake below $600 \mathrm{mg} /$ day received either a Ca supplement of $1,500 \mathrm{mg} /$ day $(N=231)$ or a placebo $(N=230)$ (8). There were no bone mass or density measurements of either the mother or her offspring. However, in addition to other biometric measurements, femoral and humeral diaphysis length of the fetus was measured. No differences were found in fetal biometric measurements between the supplemented or placebo groups. Similarly, neonatal characteristics and anthropometric measurements at delivery were comparable in both groups. They concluded that $\mathrm{Ca}$ supplementation of $1,500 \mathrm{mg} /$ day in pregnant women with low $\mathrm{Ca}$ intake did not appear to impact on fetal somatic or skeletal growth.

A longitudinal follow-up of a Tasmanian birth cohort, mainly of Caucasian origin, was used to describe the association between maternal dietary intake in the third trimester of pregnancy and bone mass in their offspring at the age of 16. Maternal Ca intake was positively associated with lumbar spine BMD, but no association was found between femoral neck and total body bone mass. After including all significant nutrients into the same multivariate regression model, $\mathrm{Ca}$ intake was no more significant (9).

\section{Bone health in adulthood}

Optimally, after puberty and throughout most of adulthood, bone formation and resorption are balanced. During this period, bone mass is consolidated, and $\mathrm{Ca}$ requirements are relatively stable. Peak bone mass, the maximum amount of bone that can be accumulated, is reached in early adulthood $(10,11)$. The ability to attain peak bone mass is affected by genetic background and by lifestyle factors, such as physical activity and total $\mathrm{Ca}$ intake. Bone is a dynamic tissue, and a number of clinical studies suggest that increasing bone mass early in life has a transient effect, but does not confer protection against later bone loss and osteoporosis (12). The Ca content of bone at maturity is approximately $1,200 \mathrm{~g}$ in women and $1,400 \mathrm{~g}$ in men $(13,14)$. In men, this level remains 
relatively constant until the onset of age-related bone loss later in life, and in women until the onset of menopause. Caucasian women appear to lose as much as $3-10 \%$ of their trabecular bone per year during the first few years after menopause and about $1 \%$ of their cortical bone per year during the first decade after menopause. After this accelerated bone loss period, the loss again levels off during the postmenopausal years. Lifetime losses may reach $30-40 \%$ of peak bone mass among women and 20-30\% among men (15).

Bone health in premenopausal women

Data are scarce with respect to bone health (mass and fractures) in premenopausal women. We did not find any SR data from this millennium reporting effects of Ca supplementation on premenopausal women's bone health.

Bone health in postmenopausal women

Postmenopausal women are the most common target populations for research regarding bone health. We found one SR (graded C) and two meta-analyses (graded A and C).

The SR by Waugh et al. (16) evaluated risk factors for low BMD among 40- to 60-year-old women. They found an inconsistent evidence of an association between the current $\mathrm{Ca}$ intake and BMD (four studies) and insufficient evidence of an association between the past $\mathrm{Ca}$ intake and BMD (one study). None of these studies were intervention studies, and $\mathrm{Ca}$ intake was self-reported. They concluded that evidence of an association between the current $\mathrm{Ca}$ intake and BMD was inconsistent and insufficient for past $\mathrm{Ca}$ intake and BMD.

The meta-analysis of Shea et al. (17) included 15 RCTs with Ca supplementations ( $N=1,806$, out of them 953 were $\mathrm{Ca}$ supplemented). The pooled mean (95\% CI) difference in bone loss between the supplemented and placebo groups in percentage change from baseline was $1.66 \%(0.92-2.39 \%)$ for the lumbar spine (nine studies), $1.64 \%(0.70-2.57 \%)$ for the hip (eight studies), and $1.91 \%$ $(0.33-3.50 \%)$ for the distal radius (six studies) favoring the Ca supplementation. They concluded that Ca supplementation alone had a small positive effect on bone density.

Chung et al. (18) included in their large review the Ottawa EPC report (19) and did an update search of RCTs published after that. The review did not separate Ca trials from $\mathrm{Ca}$ in combination with vitamin $\mathrm{D}$ trials. The Ottawa EPC report concluded that overall, there is good evidence that combined vitamin $\mathrm{D}_{3}$ and $\mathrm{Ca}$ supplementation resulted in small increases in BMD of the spine, total body, femoral neck, and total hip. The update search of Chung et al. (18) did not find evidence to change this conclusion, although quantitative synthesis was limited due to variable treatment durations and BMD sites.

\section{Bone health in men}

The data evaluating the effect of $\mathrm{Ca}$ intake on bone health in men are scarce. We found one SR (graded C) of Papaioannou et al. (20). They included 14 studies in their assessment of BMD and $\mathrm{Ca}$ intake in men (5 longitudinal and 9 cross-sectional studies). Cross-sectional studies showed inconsistent evidence. Five studies showed a positive association between $\mathrm{Ca}$ intake and BMD of the lumbar spine and hip, whereas four studies did not find an independent association between $\mathrm{Ca}$ intake and BMD at these bone sites. Also, the five longitudinal studies showed inconsistent evidence. In two studies, $\mathrm{Ca}$ intake was associated with bone loss. In particular, men in the lower quartiles of $\mathrm{Ca}$ intake $(<1,100 \mathrm{mg} /$ day $)$ had approximately double the rate of bone loss. On the other hand, three studies did not predict bone loss.

Men with low $\mathrm{Ca}$ intake were underrepresented in these studies. When the participants were classified into quartiles by dietary $\mathrm{Ca}$ intake, the limit of the lowest quartile was $<1,100 \mathrm{mg} /$ day, which is mainly seen to be a sufficient $\mathrm{Ca}$ intake. The authors concluded that the existing data were inconsistent and did not show that Ca intake (dietary or supplements) could predict bone loss.

Fractures

We found one SR (graded A), three meta-analyses (one graded $\mathrm{A}$, two graded $\mathrm{C}$ ), one cohort study (graded $\mathrm{C}$ ), and one cross-sectional study (graded $\mathrm{C}$ ) relating $\mathrm{Ca}$ intake and fractures.

Shea et al. (17) found only five RCTs that measured fracture rate in a meta-analysis from 2002. The study found no significant reduction in either vertebral fracture risk ratio ( $\mathrm{RR}, 95 \% \mathrm{CI})$ being $0.77(0.54-1.09)$ or in non-vertebral fractures, RR 0.86 (0.43-1.72). They also concluded that the magnitude of reduction in fracture risk with $\mathrm{Ca}$ supplementation alone remains an open question.

Tang et al. (21) reported in their meta-analysis whether $\mathrm{Ca}$ or $\mathrm{Ca}$ in combination with vitamin $\mathrm{D}$ prevents fractures and bone loss. Twenty-nine studies were included in the analyses, out of them 17 reported all types of fractures as an outcome and 24 reported BMD. In total, 64,897 individuals 50 years or older, of them $92 \%$ women, were included. In 16 trials, participants received Ca-only supplements. Effect of $\mathrm{Ca}$ only on fracture risk reduction (RR; 95\% CI) was 0.90 (0.80-1.00). The difference in RR between Ca-only supplementation and $\mathrm{Ca}$ with vitamin $\mathrm{D}$ combination was very small $(0.90$ vs. 0.87$)$ and was not significant. The treatment effect was greater in participants whose daily intake was low (less than $700 \mathrm{mg}$ /day). They concluded that the fracture risk reduction was greater in the trial in which the compliance rate was high. In addition, the treatment effect was better with $\mathrm{Ca}$ doses of 1,200 mg/day or more. 
Instead of all types of fractures, Bischoff-Ferrari et al. (22) assessed in their meta-analysis the relationship of $\mathrm{Ca}$ intake to the risk of non-vertebral and hip fractures. In the included five RCTs, Ca supplementation varied between 800 and 1,600 mg/day and was compared with the placebo. Among 6,740 participants (5,666 primarily postmenopausal women and 1,074 men), the pooled risk ratio (RR; 95\% CI) for non-vertebral fractures was nonsignificant, $0.92(0.81-1.05)$. The pooled risk of four RCTs with separate results for hip fracture $(n=6,504,139$ hip fractures) was 1.64 (1.02-2.64). Pooled results from seven prospective cohort studies $(N=170,991$ women, 2,954 hip fractures) found no association between $\mathrm{Ca}$ intake and hip fracture risk (RR per $300 \mathrm{mg}$ total Ca per day $=1.01 ; 0.97-1.05)$. They concluded that $\mathrm{Ca}$ intake was not significantly associated with hip fracture risk in women or men based on pooled results from prospective cohort studies. The pooled results from RCTs showed no reduction in hip fracture risk with $\mathrm{Ca}$ supplementation, and an increased risk was possible.

The Ottawa EPC report (19) was included in the SR of Chung et al. (18). The authors concluded that Ca supplementation in combination with vitamin D (most studies used $\mathrm{D}_{3}$ ) is effective in reducing fractures and falls in institutionalized populations, but there is inconsistent evidence in reducing falls in postmenopausal women and older men. The update search of Chung et al. (18) identified one new RCT of female Navy recruit, aged 17-35, which showed that vitamin D (800 IU/day) in combination with $\mathrm{Ca}$ (2,000 $\mathrm{mg} /$ day) supplementation can reduce the risk of stress fractures from military training compared to placebo.

In a Swedish cohort study, Warensjö et al. (23) evaluated the association between $\mathrm{Ca}$ intake and risk of fractures ( $n=61,433$ women born between 1914 and 1948) and osteoporosis (subcohort of 5,022 women). The participants were divided into quintiles by $\mathrm{Ca}$ intake, and the third quintile was used as a reference group (range of mean Ca intake: 882-992 mg/day). The HR for the first event of any fracture was 1.18 (1.12-1.25) and for hip fracture $1.29(1.17-1.43)$ in the lowest quintile (Ca intake $<751 \mathrm{mg} /$ day). The risk for osteoporosis was also higher the OR being 1.47 (1.09-2.00). The highest quintile of $\mathrm{Ca}$ intake did not further reduce the risk of fractures of any type, or of osteoporosis, but was associated with a higher rate of first-event hip fracture (HR 1.19; 1.06-1.32).

In their cross-sectional study, Zhong et al. (24) evaluated the association of $\mathrm{Ca}$ intake and dietary protein intake with risk of fractures in postmenopausal women aged 50 years or older. They did not find a relationship between total $\mathrm{Ca}$ intake and risk of fractures. However, the cross-sectional nature does not permit assessment of causality, and establishing the effect of Ca supplementa- tion on fractures would require large, relatively long trials measuring fracture incidence.

\section{Pregnancy-related outcomes}

We found two high-quality and one good quality systematic reviews on the effects of Ca during pregnancy (Evidence Table 2). The other included studies, one RCT and one cohort study, had serious flaws in their study design. Only the results of at least good quality studies are reviewed here.

\section{Offspring}

Buppasiri et al. (25) reviewed 21 RCTs involving 16,602 pregnant women. They found a significant increase of approximately $65 \mathrm{~g}(95 \%$ CI 16-114 g) in birth weight in children whose mothers had used $\mathrm{Ca}$ supplements during pregnancy compared to babies of non-users (19 trials, 8,287 women; Evidence Table 2). No significant differences were, however, found in infant with low birth weight between the two groups.

In the systematic review by Bergel et al. (26) of two RCTs and three observational studies, no consistent effect was found on the blood pressure of infants. However, in children aged 1-9 years, higher maternal $\mathrm{Ca}$ intake (dietary or from supplements) was associated with lower systolic blood pressure (mean: $1.92 \mathrm{mmHg}$, 95\% CI $0.71-$ $3.14 \mathrm{mmHg}$ ). No association with diastolic blood pressure was found. This finding was supported by another systematic review of Hofmeyr et al. (27), which found that the risk of childhood systolic blood pressure greater than 95th percentile was reduced (514 children: RR 0.59, 95\% CI 0.39-0.91).

Mother

Hofmeyr et al. (27) reviewed 13 randomized trials comparing at least $1 \mathrm{~g}$ daily of $\mathrm{Ca}$ during pregnancy with a placebo. They found that the risk of high blood pressure was reduced by 35\% (12 trials with 15,730 women, $\mathrm{RR}=0.65,95 \%$ CI $0.53-0.81$ ), the effect being greatest in women with low baseline $\mathrm{Ca}$ intake. In four small trials among women at high risk of developing pre-eclampsia (568 women: RR 0.45, 95\% CI 0.24-0.83), the risk of pre-eclampsia was reduced by $55 \%$.

The results on preterm birth were inconsistent. Hofmeyr et al. (27) reported that the average risk of preterm birth was reduced in the $\mathrm{Ca}$ group overall (11 trials, 15,275 women: RR 0.76; 95\% CI 0.60-0.97). In a systematic review by Buppasiri et al. (25), there were no statistically significant differences between women who received $\mathrm{Ca}$ supplementation and those who did not in terms of reducing preterm births (less than 37-week gestation) (RR 0.90; 95\% CI 0.73-1.11; 12 studies, 15,615 women; random-effects model) and also in less than 
34-week gestation (RR 1.11; 95\% CI 0.84-1.46; three trials, 5,145 women).

Lactation

We did not find any SR regarding relationships between $\mathrm{Ca}$ intake and lactation.

\section{Cancer}

Nine studies (five SR, one meta-analysis, three cohort studies) with cancer as an outcome were included (Evidence Table 3). Of these 9 studies, 2 SRs were ranked as high quality and three cohorts as good quality studies. $\mathrm{Ca}$ intake did not have a consistent association with different types of cancers; some of the studies showed protective effect and in some studies $\mathrm{Ca}$ was associated with an increased risk of some type of cancers.

In the three studies of which one was meta-analysis (28), one systematic review (18) and one cohort study (29) having breast cancer as an outcome, $\mathrm{Ca}$ intakes were associated with a lower risk of breast cancer (28) in premenopausal women only (18) and tended to have an association in the third study (29).

$\mathrm{Ca}$ intake was associated with lower risk of recurrence of colorectal adenomas in one high-quality SR (30) and in another SR (31) but not with the risk of colorectal cancer in SR (30) in the general population.

High $\mathrm{Ca}$ intake was associated with slightly increased risk of prostate cancer in two of the three studies (18, $32,33)$. Only one of these studies was ranked high quality.

No significant associations were found with endometrial cancer (34), lung cancer (35), or total cancer (18).

\section{Cardiovascular outcomes}

Thirteen studies (seven SRs, three RCTs, three cohort studies) addressed different types or cardiovascular outcomes (Evidence Table 4). Three of the SRs were ranked giving high-quality evidence; one SR, one RCT, and one cohort were ranked as good quality studies. No consistent evidence of $\mathrm{Ca}$ intake with other cardiovascular outcomes other than systolic blood pressure was found in these studies.

$\mathrm{Ca}$ intake or Ca supplementation was not significantly associated with increased or reduced risk of aortic valve calcification, coronary artery calcification (CAC) (36), increased serum lipids $(36,37)$, stroke or death $(36,38)$ or cardiovascular disease mortality (39), atherosclerosis vascular disease (40), cardiovascular events (41) or abdominal aortic calcification or coronary aortic calcification (42). In one study (43), Ca supplementation was associated with increased risk of myocardial infarction but not in the others $(40,41)$. In the only included study that had diabetes as an outcome (44), the higher $\mathrm{Ca}$ intake was associated with reduced risk of type 2 diabetes.

The cardiovascular outcomes with $\mathrm{Ca}$ intake during pregnancy are reported in pregnancy-related outcomes.

Ca supplementation lowered systolic blood pressure with $2-4 \mathrm{mmHg}$ in hypertensive and in pregnant women $(18,27,45)$ in three high-quality SRs. One RCT found a small effect on blood pressure in those with below median Ca intakes (37).

\section{Obesity and control of body weight}

Three systematic reviews, of these two high quality (18, $46,47)$ and two randomized clinical trials $(37,48)$ with body weight and/or obesity as an outcome, were included in this review (Evidence Table 5). No consistent effect was found. In only one SR (seven RCTs, 794 subjects) (47), a mean difference of -0.74 and $-0.93 \mathrm{~kg}$ body fat favoring higher $\mathrm{Ca}$ intake was found. The studies reviewed did not show convincing evidence or a favorable effect of $\mathrm{Ca}$ intake on body weight.

\section{Total mortality}

Mortality as an outcome was assessed in five studies (two SRs and three cohort studies), of which one SR was ranked high quality (Evidence Table 6). No consistent effect was found of $\mathrm{Ca}$ intake on death of various causes. The results varied from increased risk of death of cardiovascular causes $(43)$, to no effect $(18,43)$, to about $10-25 \%$ decreased risk all-cause death $(38,39,49)$ with higher $\mathrm{Ca}$ intake.

Upper intake level

We did not find any dose-response data to evaluate the safety limits of upper intake level. We included only clinical outcomes, such as all-cause mortality, cancer, and cardiovascular events. The results of these outcomes have been described in previous sections. Briefly, we did not find that calcium/dairy intake is associated with an increased risk of mortality. On the contrary, all-cause mortality was lowest in those with the highest use of $\mathrm{Ca}(38,39,49)$. The results with relationship to cancer showed either no relationship or high $\mathrm{Ca}$ intake having a protective association. Prostate cancer was an exception with inconsistent results. However, observational studies suggested an increased risk of prostate cancer among men with high daily $\mathrm{Ca}$ intake of more than $2,000 \mathrm{mg}$ $(32,33)$.

\section{Discussion}

The aim of this review is to find a scientific base for a Nordic recommendation for dietary intake of $\mathrm{Ca}$. We analyzed the literature on the relationships between $\mathrm{Ca}$ intake and different health outcomes. We focused on 
published systematic reviews but included a few RCTs and cohort studies. Some of the SRs included observational studies as well as RCTs. The quality of the SRs varied from $\mathrm{A}$ to $\mathrm{C}$, while none of the other type of studies reached the score of $\mathrm{A}$.

\section{Main findings in relationship to the research questions}

Dose-response assessment including exposure range

The difference in $\mathrm{Ca}$ intake between the studies, some estimating total $\mathrm{Ca}$ intake, some concentrating on supplemented $\mathrm{Ca}$, and some neglecting the supplemental use assessing only dietary intake, complicates the interpretation of $\mathrm{Ca}$ effects. Also, the methodology of assessing dietary $\mathrm{Ca}$ intake varies widely from dietary records of several days and validated food frequency questionnaires (FFQs) to enquire the use of milk in general. Amount of milk and milk products, the richest and most important $\mathrm{Ca}$ source in Nordic countries, is fairly stable simplifying the estimation of $\mathrm{Ca}$ intake, which is still challenging. Although the participants are willing to record their diet to the best of their ability, there may be a discrepancy between actual and reported $\mathrm{Ca}$ intake. The most common method is an FFQ with varying number of items on the list. If the FFQ is validated for the study at issue, it mainly works well, but often the FFQ is done for different purposes, for different age groups or even for different ethnic groups. Single 24-h recalls have a problem, because individual estimates may not represent usual intake.

The use of terminology is not always clear. Some studies use the term $\mathrm{Ca}$ supplementation but also include the use of vitamin $\mathrm{D}$ in combination with $\mathrm{Ca}$ supplements. Thus, it is not possible to evaluate the sole $\mathrm{Ca}$ effect. Owing to increasing interest in vitamin $\mathrm{D}$ and health, recent studies focus on the use of $\mathrm{Ca}$ in combination with vitamin $\mathrm{D}$, or the comparison is done between $\mathrm{Ca}$ and $\mathrm{CaD}$ without pure placebo groups. Selfreported uses of $\mathrm{Ca}$ supplements may have been asked with one question without any further enquiry about name or quantity of the ingredient.

\section{Health outcomes}

Bone health

Methodological inadequacies are the biggest limitation in evaluating factors affecting bone health. Dual energy X-ray absorptiometry (DXA) provides a reasonable overall description of bone density, which is a measure of mineral content of the bone, but overlooks geometric alterations that can influence bone strength. However, it is ultimately the whole bone structure, that is, its shape and size, mean cortical thickness, cortical, and trabecular density not its mass, mineral content, or areal density (BMC or BMD) that determines bone mechanical competence. Although BMD correlates directly with the change in bone mass, it does not take into account possible dimensional, material, or structural properties of bone, and is subject to inherent uncertainty $(50,51)$. A consideration of geometric properties emphasizes that both the amount and location of bone mineral are important. Age-related loss of bone mass is not necessarily accompanied by a proportionate age-related loss of bone strength because geometric adaptation may compensate for the loss. Age-related cortical thinning of long bone shafts, for example, is associated with increased bone girth, a compensatory change that tends to increase structural rigidity (52).

Although BMD measured with planar DXA is the most prevalent outcome in bone research, it does not represent well all determinants of bone geometric properties. However, thus far there is limited research evaluating effects of dietary or supplemental $\mathrm{Ca}$ on bone strength or structure.

In their reviews among children, Winzenberg et al. (6) included studies with $\mathrm{Ca}$ supplements, while Huncharek et al. (7) reviewed works with dietary $\mathrm{Ca}$ and dairy products. $\mathrm{Ca}$ intake affected bone mass positively, and although the effect was small, $\mathrm{Ca}$ intake was crucial in childhood and youth. Furthermore, the benefit was especially seen in children with low baseline $\mathrm{Ca}$ intake. It is likely that $\mathrm{Ca}$ intake is a necessary but insufficient condition for the development of a strong skeleton. However, the results do not support the general use of $\mathrm{Ca}$ supplementation in healthy children. Adequate vitamin D intake may have an essential factor when assessing the role of $\mathrm{Ca}$ intake. There are also some findings that low $\mathrm{Ca}$ intake is more harmful when associated with low vitamin D status (53).

Most studies on the effects of $\mathrm{Ca}$ intake on adult bone mass concerned postmenopausal women. We were not able to find any recent SRs about $\mathrm{Ca}$ intake and bone health in premenopausal women after the review of Welten et al. from the year 1995, where they analyzed the relationship between $\mathrm{Ca}$ intake and bone mass among young adults between 18 and 50 years of age (54). They included 33 studies and only 4 of them were intervention studies. The cross-sectional studies in women suggested a positive association between $\mathrm{Ca}$ intake and bone mass. Also, the few intervention studies found a consistent positive effect of a Ca supplement of about 1,000 mg/day on bone mass. These studies suggest that $\mathrm{Ca}$ intake should be at least $800 \mathrm{mg} /$ day to optimize bone mass.

Due to high heterogeneity, inconsistent results, lack of RCTs, and limited number of other kind of studies (one SR included five longitudinal and nine crosssectional studies), it is not possible to make any conclusions in the case of men. 
In postmenopausal women, a positive treatment effect on BMD was evident in most studies. Ca supplementation had a relatively small, but possibly meaningful, effect in reducing bone loss (17). Ca in combination with vitamin $\mathrm{D}_{3}$ supplementation resulted in small increases in BMD of the spine, femoral neck, and total hip. Based on included trials, it was less certain whether vitamin D3 supplementation alone has a significant effect on BMD $(18,21)$.

\section{Fractures}

The evidence that $\mathrm{Ca}$ supplementation reduces fracture incidence is less and inconsistent. Pooled results from cohort studies did not find significant associations between the total $\mathrm{Ca}$ intake and hip fracture risk in women or men (22). Also, a longitudinal follow-up of a Swedish cohort showed increased risk of fragility fractures and osteoporosis in women with $\mathrm{Ca}$ intake below $751 \mathrm{mg} /$ day. In that cohort, women with the highest $\mathrm{Ca}$ intake ( $>1,137 \mathrm{mg} /$ day) had increased risk of first-event hip fracture (23). On the other hand, in the meta-analysis of Tang et al. (21), the treatment effect was better with doses at or above $1,200 \mathrm{mg} /$ day than with lower doses, and in individuals who were elderly, had low dietary Ca intake ( $<700 \mathrm{mg} /$ day), or were compliant with $\mathrm{Ca}$ supplementation ( $>80 \%$ ) (21). However, participants were mainly women, and the data are limited for men. Furthermore, Ca supplementation with vitamin D may be effective in reducing fractures in institutionalized populations although the influence remains controversial in general population (18).

As a general conclusion, $\mathrm{Ca}$ is essential for bone health. Although $\mathrm{Ca}$ is only one factor contributing to bone mass and strength, it is essential for correct bone development, and especially in individuals with a low intake, sufficient $\mathrm{Ca}$ intake will reduce, but not prevent bone loss. Increased $\mathrm{Ca}$ intake suppresses the number of bone-remodeling sites and augments premature mineralization of immature bone, leading to an apparent increase in bone density. Net bone accumulation will be greater as $\mathrm{Ca}$ intake increases to the point of genetic program governing growth. Further increases in $\mathrm{Ca}$ intake will produce no further bone accumulation. This may be different for different stages of growth (55). It has also been found in postmenopausal women that the rate of bone loss is significantly lower in the first year of $\mathrm{Ca}$ supplementation than in the second year, especially at regions where more than half of the bone content is of the trabecular type. Furthermore, the long-term (3-4 years) preservation of bone by $\mathrm{Ca}$ supplements has been found mainly at sites with a predominance of cortical bone, such as the radius and total body, with an annual turnover rate of only $2-3 \%$. This slow rate of cortical bone turnover implies that a steady state is reached many years later than in trabecular bone. The long-term effect of additional $\mathrm{Ca}$ on bone density and fracture prevention is therefore not readily revealed by or extrapolated from randomized bone density studies (56).

Ca supplementation may transiently increase BMD by reducing the rate of bone remodeling. Increases in bone mass appear to occur primarily in cortical bone sites, are most apparent among populations with low $\mathrm{Ca}$ intake, and do not seem to persist beyond the Ca supplementation period.

Pregnancy-related outcomes

Offspring. The evidence regarding maternal $\mathrm{Ca}$ intake and offspring's health is scarce and contradictory. In their RCT, Abalos et al. (8) did not find any difference in fetal growth between fetuses of women with or without $\mathrm{Ca}$ supplements. However, a small increase of $65 \mathrm{~g}$ in birth weight was found in SR of Buppasiri et al. (25). This increase is most likely not clinically important, and due to high heterogeneity this result must be interpreted with caution. There was no difference in other pregnancy and infant outcomes (25).

Some results support an association between maternal $\mathrm{Ca}$ intake during pregnancy and offspring systolic blood pressure among children $(26,27)$. The evidence is more consistent among children older than 1 year (26).

Mother. Ca supplementation is associated with a significant protective benefit in the prevention of preeclampsia especially in women with low baseline $\mathrm{Ca}$ intake $(18,27)$. The average risk of high blood pressure was also reduced with $\mathrm{Ca}$ supplementation compared with a placebo $(18,27)$. Since pre-eclampsia is a dangerous life-threatening disorder, in which hypertension arises, Ca supplementation may be one factor in reducing the risk of this serious medical condition. Since pre-eclampsia is a dangerous life-threatening disorder, in which hypertension arises, in women with low $\mathrm{Ca}$ intake $\mathrm{Ca}$ supplementation may be one factor in reducing the risk of this serious medical condition.

However, there was no evidence that $\mathrm{Ca}$ supplementation had any effect on maternal weight gain during pregnancy (25).

Lactation. Profound changes in $\mathrm{Ca}$ metabolism and bone mineral status accompany pregnancy both during gestation and after delivery and lactation. Accumulating data suggest that the losses are independent of maternal $\mathrm{Ca}$ intake, and largely reversible in subsequent lactation and after the end of breast-feeding, possibly in connection with the return of menses $(57,58)$. This does not imply that good nutrition, including the maintenance of adequate $\mathrm{Ca}$ intake, is important during lactation. However, the accumulating data suggest that breastfeeding women need not consume excess Ca (59). 
Cancer. In general, no association has been found between increasing $\mathrm{Ca}$ intakes and cancer incidence or mortality (Chung et al. 2009). However, there are inconsistent findings considering different cancer types. In women, there was a trend toward lower breast cancer risk for those with high $\mathrm{Ca}$ intake $(18,29,60)$.

The results concerning prostate cancer are inconsistent showing slightly increased association, no association or inverse association between $\mathrm{Ca}$ intake and risk of prostate cancer $(18,32,33)$. The results of Kristal et al. do not simplify the interpretation. They report that dietary $\mathrm{Ca}$ intake was positively associated with lowgrade cancer but inversely associated with high-grade cancer.

The results are not unambiguous in aspects of colorectal cancer, either. Although there are some findings that high Ca intake may contribute, to a moderate degree, to the prevention of adenoma polyps recurrence especially in patients with a history of adenomas, no apparent effect was seen in advanced adenomas or in populations at lower risk $(18,30,31)$. More evidence is needed to recommend the general use of $\mathrm{Ca}$ supplements to prevent colorectal cancer.

The current evidence for a role of $\mathrm{Ca}$ in endometrial carcinomas is too limited to draw any conclusions (34). Similarly, more evidence is needed about the relationship between $\mathrm{Ca}$ intake and lung cancer, although increased total $\mathrm{Ca}$ intake reduced lung cancer risk in a subgroup of current smokers and a beneficial trend was seen in women (35).

\section{Cardiovascular outcomes}

Hypertension and blood pressure. Fairly consistent evidence suggests that $\mathrm{Ca}$ supplementation lowered systolic blood pressure among hypertensive adults, but no significant effect has been found on diastolic blood pressure or in normotensive individuals $(18,37,45)$.

More data are needed about influences of age, sex, $\mathrm{Ca}$ dose, background dietary $\mathrm{Ca}$, and supplement versus dietary source on blood pressure.

No consistent evidence of the relationship between $\mathrm{Ca}$ intake and other cardiovascular outcomes was found (36, 37, 39-41, 43). Even a possible increased risk concerning cardiovascular events is inconclusive.

Cardiovascular events. Recently, concern has arisen of an increased risk of cardiovascular events associated with $\mathrm{Ca}$ supplementation. Bolland et al. (43) suggested an upward trend in cardiovascular events in older people taking Ca. However, there are several limitations. Cardiovascular events were not a primary outcome, the events may not have been well adjudicated, the studies included are small and the event frequency is low. Moreover, the total $\mathrm{Ca}$ intake was not reported, and the supplementation was generally $1,000-1,200 \mathrm{mg} /$ day. The events may therefore be associated with intakes higher than the supplemented dose, perhaps more than 2,000 $\mathrm{mg}$ of calcium per day. So, it is difficult to conclude that $\mathrm{Ca}$ intakes per se in the range of 1,000-1,200 mg/day can be associated with cardiovascular events (60). There are also opposing findings with no increase in cardiovascular events $(40,41)$, and supplements may even improve some vascular risk factors, e.g., blood pressure $(37,45)$.

\section{Diabetes}

Although Pittas et al. (44) found an inverse association between $\mathrm{Ca}$ or dairy intake and type 2 diabetes or metabolic syndrome, they concluded that the evidence is limited because most observational studies are of low quality, whereas duration of intervention studies was short, included few participants, or did post-hoc analyses.

Body weight/obesity

No convincing findings regarding benefits of $\mathrm{Ca}$ supplementation on body weight loss or weight maintenance were found. Ca supplementation did not alter weight or fat gain $(18,37,46,47)$.

\section{Total mortality}

The evidence relating total mortality is inconsistent. There is some proof about increased death of cardiovascular events (43), also a protective effect of Ca intake, especially on all-cause mortality $(39,49,61)$, or no effect $(18,43)$. There are considerable differences between the works showing a protective influence, which complicates the interpretation. Mursu et al. (49) reported the use of $\mathrm{Ca}$ supplements in relationship to total mortality in older women, whereas Kaluza et al. (39) assessed dietary Ca intake in middle-aged or older men. The follow-up time of 65 years of van der Pols et al. (38) is considerable. Although the results suggest a beneficial effect of high dairy consumption in childhood on total mortality in adulthood, environmental and socio-economic circumstances have changed during the follow-up period, but these changes are impossible to be considered in the analysis. A much smaller challenge is the difficulty in separating the $\mathrm{Ca}$ effect from the total diet. One possible interpretation is that high dairy consumption is one factor in a healthy balanced diet. Also, it is difficult to compare the results of Bolland et al. (43) (supplement users, mainly women) and Chung et al. (18), whose result is based on total Ca intake in one cohort of adult men and their spouses.

Adverse effects

$\mathrm{Ca}$ is mainly thought of to be a safe nutrient to be used as a supplement, although recently there has been much of debate in the literature about the possible adverse effects of high $\mathrm{Ca}$ supplementation. Discordant data provided limited proof of the unfavorable effects of high calcium/dairy intake. So far, only a few studies on the 
whole have reported adverse intestinal discomfort, such as constipation and gas, being apparently related to the Ca supplements (18).

Kidney stone formation is an adverse outcome, most notably among postmenopausal women. However, the levels of $\mathrm{Ca}$ intake that may cause kidney stones within a normal population cannot be specified with certainty and are known to be vary depending on a number of factors, including baseline renal function, pre-existing disease conditions, and interactions with drugs (61).

In the past, milk-alkali syndrome was often a side effect of treating peptic ulcer disease with antacids containing $\mathrm{Ca}$. It is rarely seen today, because newer, better medications that do not contain $\mathrm{Ca}$ are available for treating ulcers. A more common scenario today is when someone takes excess calcium carbonate in an attempt to prevent osteoporosis. Calcium deposits in the kidneys and in other tissues can occur in milk-alkali syndrome. High levels of vitamin D can worsen this condition. This has been reported in persons who take $2 \mathrm{~g}$ or more of calcium per day. Though the modern management of peptic ulcer disease has radically changed over the past decades, milk-alkali syndrome may still occur, especially in patients who self-medicate for symptoms of dyspepsia (62).

Doses

The total $\mathrm{Ca}$ intake has not been assessed in most of the studies. There is a huge variation in daily $\mathrm{Ca}$ intake. Few studies have assessed total $\mathrm{Ca}$ intake including dietary and supplemented Ca. Many studies using supplements have not asked about dietary $\mathrm{Ca}$ intake, but on the other hand some studies assessing dietary $\mathrm{Ca}$ intake have neglected the possible use of supplements. Dose-response studies have not been performed.

Study duration

Study duration varied from a short few weeks' interventions to follow-ups of several years. Short interventions may be enough to show changes in blood pressure or serum lipids, whereas evaluation of $\mathrm{Ca}$ intake on bone density takes at least a few months and cardiovascular events, cancer or fragility fractures need an exposure of several years.

Heterogeneity

Owing to heterogeneity in the studies, it is difficult to interpret the results and provide single summary statement. The sources and dose of $\mathrm{Ca}$ vary widely among the studies, as well as the methods used to assess the amount consumed. For many risk factors, the quality and strength or direction of association varies among studies. Study cohorts were mainly Caucasian participants.

Substantial differences exist across the studies in many important factors. Many of the studies enrolled participants with sufficient or near-sufficient $\mathrm{Ca}$ intake, whereas in others baseline $\mathrm{Ca}$ intake was well below the recommended level, especially in reports from Asian populations which were included in the SRs. Also, the relatively large range in supplemental doses may complicate the comparison. Compliance has mostly not been reported or taken into account.

\section{Limitations}

Most studies tested $\mathrm{Ca}$ supplementation, not total $\mathrm{Ca}$ intake, i.e., dietary $\mathrm{Ca}$ and supplementation. However, the effect of $\mathrm{Ca}$ intake may differ according to baseline $\mathrm{Ca}$ intake. Evaluation of $\mathrm{Ca}$ intake in groups, where mean $\mathrm{Ca}$ intake is above the recommended daily intake may mask individuals with low habitual intake or $\mathrm{Ca}$ deficiency. In addition, several studies examined $\mathrm{Ca}$ with vitamin $\mathrm{D}$ supplementation, or the participants are allowed to use multivitamins and even other $\mathrm{Ca}$ or vitamin $\mathrm{D}$ supplements were used simultaneously, which makes it difficult to interpret the results.

\section{Conclusions}

We did not find solid evidence for changing the Nordic recommendations from 2005. Although calcium/dairy supplementation had a marginal impact on bone health in the studies, milk and dairy products has to be considered to be an optimal source of $\mathrm{Ca}$ in the Nordic setting with important effects on bone health. Regarding children, the effect of $\mathrm{Ca}$ supplementation on the skeleton remained small, but most studies included children with adequate $\mathrm{Ca}$ intake. It is likely that $\mathrm{Ca}$ supplementation has a much greater impact on bone mass accretion in children with low baseline Ca intake. Similarly in adults, the treatment effect seems to be greater in participants with low daily $\mathrm{Ca}$ intake.

It is also difficult to separate the effect of $\mathrm{Ca}$ from the combination of $\mathrm{Ca}$ and vitamin $\mathrm{D}$.

In addition to skeletal health, there is evidence that high $\mathrm{Ca}$ intake has a protective influence in reducing blood pressure and pre-eclampsia. The results suggesting that high supplementary $\mathrm{Ca}$ intake has a harmful effect on health outcomes, especially on cardiovascular health or prostate cancer are not solid. However, Ca supplementation does not seem to affect weight loss or weight maintenance, and regarding relationships between $\mathrm{Ca}$ intake and other cancers, the evidence is inconsistent or contradictory.

However, if individual dietary $\mathrm{Ca}$ intake exceeds the recommendation (depending on the age group), there 
is no need to recommend $\mathrm{Ca}$ supplements for safety reasons. We recognize that these conclusions, which are based on the current evidence, might change as additional data about long-term effects of Ca supplementation become available.

\section{Implications for research}

(1) The adverse effects of increased $\mathrm{Ca}$ intake on health outcomes.

(2) Studies including both dietary and supplemental Ca.

\section{Acknowledgements}

The authors thank Birgitta Järvinen and Jannes Engqvist for the literature search. Moreover, they thank Ulla-Kaisa Koivisto and Wulf Becker for their help and support during the process.

\section{Conflict of interest and funding}

This work is supported by the Nordic Council of Ministries.

\section{Contributions of authors}

All authors contributed to methodological appraisal and data extraction.

All authors decided independently and then by consensus which studies met inclusion criteria. All authors assessed quality and extracted data from included studies. K. U.-R. prepared the draft of bone health outcomes, and M. K. and C. L-A. prepared the draft of other health outcomes. All authors drafted the discussion, commented on the draft review, and suggested changes.

\section{References}

* indicates references included in the systematic review.

1. Nordic Nutrition Recommendations 2004. Integrating nutrition and physical activity. 4th ed. Copenhagen: Nordic Council of Ministers. ISBN: 92-893-1062-6.

2. Paturi M, Tapanainen H, Reinivuo H, Pietinen P, eds. The National FINDIET 2007 Survey (In Finnish, tables, figures and summary in English). Publications of the National Public Health Institute B23/2008. Helsinki: Yliopistopaino; 2008. http://www.ktl.fi/attachments/suomi/julkaisut/julkaisusarja_b/ 2008/2008b23.pdf.

3. Becker W, Pearson M. Riksmaten 1997-1998. Uppsala: Livsmedelsverket; 2004

4. Johansson L, Solvoll K. Norkost 1997: Landsomfattande kostholdsundersokelse blant menn og kvinner i ålderen 16-79 år [A nationwide dietary survey among men and women aged 16_79 years in Norway 1997]. Oslo: Statens råd fö r ernaering og fysisk aktivitet; 1999.
*5. Vatanparast H, Bailey DA, Baxter Jones ADG, Whiting SJ. Calcium requirements for bone growth in Canadian boys and girls during adolescence. British J Nutr 2010; 103: 575-80.

*6. Winzenberg TM, Shaw KA, Fryer J, Jones G. Calcium supplementation for improving bone mineral density in children. Cochrane Database Syst Rev 2006: CD005119. doi: 10.1002/14651858.CD005119.pub2.

*7. Huncharek M, Muscat J, Kupelnick B. Impact of dairy products and dietary calcium on bone-mineral content in children: results of a meta-analysis. Bone 2008; 43: 312-21.

*8. Abalos E, Merialdi M, Wojdyla D, Carroli G, Campodónico L, Yao SE, et al. Effects of calcium supplementation on fetal growth in mothers with deficient calcium intake: a randomised controlled trial. Paediatr Perinat Epidemiol 2010; 24: 53-62.

*9. Yin J, Dwyer T, Riley M, Cochrane J, Jones G. The association between maternal diet during pregnancy and bone mass of the children at age 16. Eur J Clin Nutr 2010; 64: 131-7.

10. Bonjour JP, Theintz G, Law F, Slosman D, Rizzoli R. Peak bone mass. Osteoporos Int 1994; 4(Suppl. 1): S7-S13.

11. Haapasalo H, Kannus P, Sievänen H, Pasanen M, Uusi-Rasi K, Heinonen A, et al. Development of mass, density, and estimated mechanical characteristics of bones in Caucasian females. J Bone Miner Res 1996; 11: 1751-60.

12. Gafni RI, Baron J. Childhood bone mass acquisition and peak bone mass may not be important determinants of bone mass in late adulthood. Pediatrics 2007; 119: S131-6.

13. Anderson JJ. Calcium requirements during adolescence to maximize bone health. Am J Coll Nutr 2001; 20(Suppl. 2): S186-91.

14. Ilich JZ, Kerstetter JE. Nutrition in bone health revisited: a story beyond calcium. J Am Coll Nutr 2000; 19: 715-37.

15. Cummings SR, Kelsey JL, Nevitt MC, O’Dowd KJ. Epidemiology of osteoporosis and osteoporotic fractures. Epidemiol Rev 1985; 7: 178-208.

*16. Waugh EJ, Lam MA, Hawker GA, McGowan J, Papaioannou A, Cheung AM, et al. Risk factors for low bone mass in healthy 40-60 year old women: a systematic review of the literature. Osteoporos Int 2009; 20: 1-21.

*17. Shea B, Wells G, Cranney A, Zytaruk N, Robinson V, Griffith $\mathrm{L}$, et al. Meta-analyses of therapies for postmenopausal osteoporosis. VII. Meta-analysis of calcium supplementation for the prevention of postmenopausal osteoporosis. Endocr Rev 2002; 23: 552-9.

*18. Chung M, Balk EM, Brendel M, Ip S, Lau J, Lee J, et al. Trikalinos TA: Vitamin D and calcium: a systematic review of health outcomes. Evidence Reprot/Technology Assessment. Number 183. AHRQ Publication No. 09-E015. August 2009.

*19. Cranney A, Horsley T, O’Donnell S, Weiler H, Puil L, Ooi D, et al. Effectiveness and safety of vitamin $\mathrm{D}$ in relation to bone health. Evid Rep Technol Assess 2007: 1-235.

*20. Papaioannou A, Kennedy CC, Cranney A, Hawker G, Brown JP, Kaiser SM, et al. Risk factors for low BMD in healthy men age 50 years or older: a systematic review. Osteoporos Int 2009; 20: $507-18$.

*21. Tang BMP, Eslick GD, Nowson C, Smith C, Bensoussan A. Use of calcium in combination with vitamin D supplementation to prevent fractures and bone loss in people aged 50 years and older: a meta-analysis. Lancet 2007; 370: 657-66.

*22. Bischoff-Ferrari HA, Dawson-Hughes B, Baron JA, Burckhardt P, Li R, Spiegelman D, et al. Calcium intake and hip fracture risk in men and women: a meta-analysis of prospective cohort studies and randomized controlled trials. Am J Clin Nutr 2007; 86: 1780-90. 
*23. Warensjö E, Byberg L, Melhus H, Gedeborg R, Mallmin H, Wolk A, et al. Dietary calcium intake and risk of fracture and osteoporosis: prospective longitudinal cohort study. BMJ 2011; 342: d1473. doi: 10.1136/bmj.d1473.

*24. Zhong Y, Okoro CA, Balluz LS. Association of total calcium and dietary protein intakes with fracture risk in postmenopausal women: the 1999-2002 National Health and Nutrition Examination Survey (NHANES). Nutrition 2009; 25: $647-54$.

*25. Buppasiri P, Lumbiganon P, Thinkhamrop J, Ngamjarus C, Laopaiboon M. Calcium supplementation (other than for preventing or treating hypertension) for improving pregnancy and infant outcomes. Cochrane Database Syst Rev 2011: CD007079. doi: 10.1002/14651858.CD007079.pub2.

*26. Bergel E, Barros AJD. Effect of maternal calcium intake during pregnancy on children's blood pressure: a systematic review of the literature. BMC Pediatr 2007; 7: 15.

*27. Hofmeyr GJ, Lawrie TA, Atallah ÁN, Duley L. Calcium supplementation during pregnancy for preventing hypertensive disorders and related problems. Cochrane Database Syst Rev 2010: CD001059.

*28. Chen P, Hu P, Xie D, Qin Y, Wang F, Wang H. Meta-analysis of vitamin $\mathrm{D}$, calcium and the prevention of breast cancer. Breast Cancer Res Treat 2010; 121: 469-77.

*29. Hjartåker A, Thoresen M, Engeset D, Lund E. Dairy consumption and calcium intake and risk of breast cancer in a prospective cohort: the Norwegian Women and Cancer study. Canc Causes Contr 2010; 21: 1875-85.

*30. Weingarten MA, Trestioreanu AZ, Yalpe J. Dietary calcium supplementation for preventing colorectal cancer and adenomatous polyps. Cochrane Database Syst Rev 2008; 23: CD003548.

*31. Carroll C, Cooper K, Papaioannou D, Hind D, Pilgrim H, Tappenden P. Supplemental calcium in the chemoprevention of colorectal cancer: a systematic review and meta-analysis. Clin Therapeut 2010; 32: 789-803.

*32. Ma RWL, Chapman K. A systematic review of the effect of diet in prostate cancer prevention and treatment. J Hum Nutr Diet 2009; 22: 187-99.

*33. Kristal AR, Arnold KB, Neuhouser ML, Goodman P, Platz EA, Albanes D, et al. Diet, supplement use, and prostate cancer risk: results from the prostate cancer prevention trial. Am J Epidemiol 2010; 172: 566-77.

*34. McCullough ML, Bandera EV, Moore DF, Kushi LH. Vitamin D and calcium intake in relation to risk of endometrial cancer: a systematic review of the literature. Prev Med 2008; 46: 298-302.

*35. Mahabir S, Forman MR, Dong YQ, Park Y, Hollenbeck A, Schatzkin A. Mineral intake and lung cancer risk in the NIH-American Association of Retired Persons Diet and Health study. Cancer Epidemiol Biomarkers Prev 2010; 19: 1976-83.

*36. Bhakta M, Bruce C, Messika-Zeitoun D, Bielak L, Sheedy P, Sarano M. Oral calcium supplements do not affect the progression of aortic valve calcification or coronary artery calcification. J Am Board Fam Med 2009; 22: 610-6.

*37. Reid IR, Ames B, Bolland MJ, Bacon CJ, Reid HE, Kyle C, et al. Effects of calcium supplementation on lipids, blood pressure, and body composition in healthy older men: a randomized controlled trial. Am J Clin Nutr 2010; 91: 131-9.

*38. van der Pols JC, Gunnell D, Williams GM, Holly JMP, Bain C, Martin RM. Childhood dairy and calcium intake and cardiovascular mortality in adulthood: 65-year follow-up of the Boyd Orr cohort. Heart 2009; 95: 1600-6.
*39. Kaluza J, Orsini N, Levitan EB, Brzozowska A, Roszkowski W, Wolk A. Dietary calcium and magnesium intake and mortality: a prospective study of men. Am J Epidemiol 2010; 171: 801-7.

*40. Lewis JR, Calver J, Zhu K, Flicker L, Prince RL. Calcium supplementation and the risks of atherosclerotic vascular disease in older women: results of a 5-year RCT and a 4.5year follow-up. J Bone Min Res 2011; 26: 35-41.

*41. Wang L, Manson JAE, Song Y, Sesso HD. Systematic review: vitamin $\mathrm{D}$ and calcium supplementation in prevention of cardiovascular events. Ann Intern Med 2010; 152: 315-23.

*42. Wang TKM, Bolland MJ, van Pelt NC, Mason BH, Ames RW, Grey $\mathrm{AB}$, et al. Relationships between vascular calcification, calcium metabolism, bone density, and fractures. J Bone Miner Res 2010; 25: 2501-9.

*43. Bolland MJ, Avenell A, Baron JA, Grey A, MacLennan GS, Gamble GD, et al. Effect of calcium supplements on risk of myocardial infarction and cardiovascular events: meta-analysis. BMJ 2010; 341: c3691.

*44. Pittas AG, Lau J, Hu FB, Dawson-Hughes B. The role of vitamin $\mathrm{D}$ and calcium in type 2 diabetes. A systematic review and meta-analysis. J Clin Endocrinol Metab 2007; 92: 2017-29.

*45. Dickinson HO, Nicolson D, Cook JV, Campbell F, Beyer FR, Ford GA, et al. Calcium supplementation for the management of primary hypertension in adults. Cochrane Database Syst Rev 2006: CD004639.

*46. Trowman R, Dumville JC, Hahn S, Torgerson DJ. A systematic review of the effects of calcium supplementation on body weight. Br J Nutr 2006; 95: 1033-8.

*47. Onakpoya IJ, Perry R, Zhang J, Ernst E. Efficacy of calcium supplementation for management of overweight and obesity: systematic review of randomized clinical trials. Nutr Rev 2011; 69: $335-43$

*48. Yanovski JA, Parikh SJ, Yanoff LB, Denkinger BI, Calis KA, Reynolds JC, et al. Effects of calcium supplementation on body weight and adiposity in overweight and obese adults: a randomized trial. Ann Intern Med 2009; 150: 821-9, W145826.

*49. Mursu J, Robien K, Harnack LJ, Park K, Jacobs Jr DR. Dietary supplements and mortality rate in older women. The Iowa Women's Health Study. Arch Intern Med 2011; 171: $1625-33$.

50. Sievänen H. A physical model for dual-energy X-ray absorptiometry-derived bone mineral density. Invest Radiol 2000; 35: 325-30.

51. Bolotin HH, Sievanen H. Inaccuracies inherent in dual-energy $\mathrm{X}$-ray absorptiometry in vivo bone mineral density can seriously mislead diagnostic/prognostic interpretations of patient-specific bone fragility. J Bone Miner Res 2001; 16: 799-805.

52. Beck TJ, Ruff CB, Scott WW Jr, Plato CC, Tobin JD, Quan CA. Sex differences in geometry of the femoral neck with aging: a structural analysis of bone mineral data. Calcif Tissue Int 1992; 50: $24-9$

53. Esterle L, Nguyen M, Walrant-Debray O, Sabatier J-P, Garabedian M. Adverse interaction of low-calcium diet and low $25(\mathrm{OH}) \mathrm{D}$ levels on lumbar spine mineralization in latepubertal girls. J Bone Min Res 2010; 25: 2392-8.

54. Welten DC, Kemper HCG, Post GB, Van Stavaren WA A meta-analysis of the effect of calcium intake on bone mass in young and middle aged females and males. J Nutr 1995; 125: 2802-13.

55. Wosje KS, Specker BL. Role of calcium in bone health during childhood. Nutrition Rev 2000; 58: 253-68. 
56. Mackerras D, Lumley T. First- and second-year effects in trials of calcium supplementation on the loss of bone density in postmenopausal women. Bone 1997; 21: 527-33.

57. Kalkwarf HJ, Specker BL, Bianchi DC, Ranz J, Ho M. The effect of calcium supplementation on bone density during lactation and after weaning. N Engl J Med 1997; 337: 523-8.

58. Holmberg-Marttila D, Sievänen H, Tuimala R. Changes in bone mineral density during pregnancy and postpartum: prospective data on five women. Osteoporos Int 1999; 10: 41-6.

59. Prentice A. Maternal calcium metabolism and bone mineral status. Am J Clin Nutr 2000; 71(Suppl): 131S-6S.

60. Bockman RS, Zapalowski C, Kiel DP, Adler RA. Commentary on calcium supplements and cardiovascular events. J Clin Densitom 2012; 15: 130-4.

61. Institute of Medicine. Dietary reference intakes for calcium and vitamin D. Washington, DC: The National Academic Press; 2010. pp. 1-44.
62. Swaminathan K. A hidden history of heartburn: the milk-alkali syndrome. Indian J Pharmacol 2011; 43: 78-9.

*Christel J. E. Lamberg-Allardt

Department of Food and Environmental Sciences, University of Helsinki

P.O. Box 66 (Agnes Sjöbergsgatan 2)

Fl-000 I 4 University of Helsinki, Finland

Tel: +358919158266

Email: christel.lamberg-allardt@helsinki.fi

*Kirsti Uusi-Rasi

UKK Institute for Health Promotion Research

P.O. Box 30

Fl-3350I Tampere, Finland

Tel: +35832829111

Fax: +35832829200

Email: kirsti.uusi-rasi@uta.fi 